\title{
Towards a Methodological Framework of Metaterminography
}

\author{
Marek LUKASIK \\ Akademia Pomorska w Słupsku/ Pomeranian University in Słupsk \\ E-mail: marek.lukasik@apsl.edu.pl,
}

\begin{abstract}
Researchers striving at establishing the academic status of a science need, inter alia, to delineate the boundaries of their area of interest, point to its object(s) of research, outline the methodology and determine its language. This process equally applies to (meta)lexicography and (meta)terminography, which are yet to prove their scientific standing. This paper attempts to pinpoint the methodological features of metaterminography and suggest a framework for a systematic study of terminographic works. The point of departure for the detailed discussions undertaken in this article are the general principles of the methodology of sciences. The work also points to the fundamental methods used in metalexicography and metaterminography and focuses on the methodological description of one of the methods used in systematic dictionary research, i.e. the terminographic analysis.
\end{abstract}

Keywords: metaterminography, methodology, terminographic analysis, terminographic work, theory

\section{Introduction}

In order to effectively carry out its activities, each science has to define itself as precisely as possible. This, inter alia, involves the indication of its object(s) of research, elaboration of its research methods as well as establishment of its own language. The degree to which a given science can self-define points to the level of its development (maturity).

Science is a specific way of knowing, which in fact creates itself ${ }^{1}$, and therefore is developing through self-control, self-correction, variation and selection. Accordingly, each science should constantly revise its own scientific apparatus (=methodology in the narrow sense ${ }^{2}$ ) so as to maintain high quality of the research results obtained. It is worth mentioning that methodological reflections follow research endeavours that have already been concluded. In this way, each contemporary science is in principle reflective (S. Kamiński 1981: 7).

The ongoing debates on the scientific status of (meta)lexicography and (meta)terminography prove that such reflections have indeed been undertaken and may eventually lead to a theory/ theories of the sciences in question. Since this is primarily the

\footnotetext{
${ }^{1}$ The development of a science leads to questions which concern the science itself. Such questions are posed mainly in relation to the validity of its [scientific] criteria and/or the correctness of its research activities (S. Kamiński 1981: 6).

${ }^{2}$ See K. Czarnecki 2009 :102.
} 
level of methodological rigour that differentiates scientific from non-scientific work (F. Grucza 2017: 29), it is therefore necessary to define the methodological framework of (meta)lexicography and (meta)terminography to establish their place in the hierarchy of sciences. Taking into account their scope of research, the task in question is (should be) undertaken by metalexicography (S.J. Schierholz 2015: 337) and by metaterminography, respectively.

This paper discusses a number of issues important for the construction of a comprehensive methodology of metaterminography, although a number of findings equally apply to metalexicography. The detailed considerations undertaken in the work are based on some general principles underlying the methodology of science, as developed on the grounds of the philosophy of science. In particular, the work focuses on the constituents of the methodology of metaterminography, such as its object of research, its overarching task and its role as a framework for any metaterminographic investigation. The paper also summarises the methods that are specific to metalexicographic and metaterminographic studies. These deliberations are followed by a methodological description of a method of systematic dictionary research known as the terminographic analysis.

\section{General considerations}

(a) The primary constitutive element of a science is its object of research, regardless of whether it is a concrete or mental entity (in fact, theoretical models of real objects/ entities may also comprise the object of research). Therefore, different sciences can primarily be differentiated on the basis of their different objects of research. The object or research will determine all the other elements of a scientific work, including its methods and research tools.

It is worth noting that objects of research may vary on account of: (i) the different part of reality to which they relate, (ii) the different set of features that an entity may exhibit, (iii) the different relations that may exist between the features, (iv) all of the above (i-iii). Also, the object of research may change as a result of internal transformations of the entities that constitute it, or as a result of the development of the science, which may take a new view (define a new scope) of the object of research.

Accordingly, each science needs to undertake constant revision of its overall methodology. Such revision may lead to the redefining of its own object of research, which in turn may result in the choice of a modified/ new set of research methods, techniques and tools. The research methods themselves can also evolve along with the changes of the object of research, however it needs to be emphasised that new/ modified methods do not constitute a distinguishing element in the differentiation of new sciences (F. Grucza 2017: 20-23).

The ultimate goal of a science is to expand knowledge about its own object of research, which involves gathering information and creating new knowledge about the object. However, the work that leads to knowledge creation has to attain an appropriate (high) level to be called scientific (F. Grucza 2017: 34). Only then can a science produce knowledge that is maximally consistent, valid, general, transparent and content-rich (J. Such 1972: 8). From the procedural point of view, only systematic study 
can be called scientific (S. Kamiński 1981: 13). The issues of systematic research work are considered (and are part of) the methodology of science in general and methodologies of particular sciences (see the following sections).

(b) Scientific work is only complete when it follows a three-stage epistemic process of diagnosis, anagnosis and prognosis. The sequence allows to gain knowledge about "present conditions, as well as its causal historical antecedents and probable future consequences" (P.J. Amopolous 2009: 192). It does not mean that, for example, research focussing on a diagnostic aspect is not scientific; it means that knowledge obtained at only one stage of the knowledge acquisition process is only partial.

The issue that is often raised in connection with science, or the scientific status of a particular research area/field, is that it should be translatable to practical applications. Yet, the degree to which the knowledge obtained in a study is relevant to practice depends on both the substance and completeness of the information gathered/ processed. Nevertheless, in principle, each science delivers knowledge that carries the applicative potential; such knowledge may contribute to the creation of a comprehensive knowledge system, i.e. one which also delivers knowledge of applicative nature (see F. Grucza 2017: 41).

Diagnosis consists in identification, definition and, most fundamentally, description of an object of research as well as explication of its present or past state(s), features and relations through direct observation. Anagnosis, on its part, is concerned with the description and explanation of past states, features and relations of a given object of research through reconstruction (derivation), as opposed to observation. As its next research step, anagnosis envisages contrastive studies aiming at synchronic comparisons of past states, features and relations of the object of research, or at bidirectional comparisons of the past and the present states, features and relations. The aim of such comparisons is to reveal the history and the progressive transformation of the variables under investigation. Both the diagnostic and anagnostic type of research work exhibit a hierarchy of research steps, from description to explication. Both types of work also reveal a specific form of interdependence; the reconstruction of the states, features and relations, as prescribed by anagnosis, starts with data obtained in diagnosis, while anagnostic knowledge helps to explain the knowledge obtained in diagnosis (F. Grucza 2017: 61-63). The prognostic work is in fact based on both diagnostic and anagnostic knowledge about the states, features and relations, aiming at forecasting their future conditions. This consists in a prognosis of their natural changes, if no influence has been exerted on the object of research, and a prognosis of induced changes, if the variables have been influenced by human intervention. Prognosis also makes it possible to forecast actual future states, features and relations of hypothetical objects, such as models (ibid: 64).

There are a number of diagnostic research questions that can be asked at each of the stages described above. At the descriptive stage, the questions include the following: Do (did) the objects really exist? How (where) do (did) they exist? What are (were) they composed of? Do (did) their features really exist? How do (did) they function? What are (were) their features? What are (were) the relations between the com- 
ponents of an object of research and/or its features? At the explication phase the relevant questions are: Why are (were) the objects the way they are (were)? Why do (did) the objects possess certain features, and not others? Why do (did) the objects function the way they do? Why do (did) the objects exhibit the relations observed? Why do (did) the objects behave the way they do (did)?

The anagnosis phase envisages questions such as: Where do the objects of research emerge from? What were the features of the objects in the past? How did the objects function in the past?

At the prognosis stage, the important research questions are: Will the observed (existing) state of affairs (i.e. the objects of research, their features and/or relations between the features) change? How will the state of affairs change? Why will it change the way it is predicted it will? How will the observed (existing) state of affairs change if it is subjected to an external intervention? What should (need to) be done, or how should we influence the object of research so that it changes (or does not change) in the desired way? What needs to be done to obtain a desired state of affairs (F. Grucza 2013: 106).

(c) Besides following a certain research sequence, each science also has to follow the general principles of scientific work. Generally derived from the definition of science, scientific work and scientific method, the rules constitute an assessment benchmark in the evaluation of research apparatus in each science. The principles include the following: 1. Research work should be consistent with scientific methods that enable a rational choice, design and methodological correctness of activities leading to the gathering of knowledge. 2. The language used should be precise and unambiguous so as to enable correct verbal presentation of research results and ensure universal understanding within a discourse community. 3 . Theses can only be deemed scientific if they have been reasonably justified. 4. A set of claims pertaining to the object of research must be internally consistent and represent a logical system. 5. All statements must be subjected to critical evaluation; each science has to ensure constant verification, revision and expansion of its existing system of scientific claims. 6. Results of scientific work should exhibit a creative nature and a potential for practical application (see, inter alia, S. Kamiński 1981; A. Rosenberg 2005; S. Pabis 2009: 14-29). As a matter of fact, it is the methodology of a science that controls the adherence to the principles outlined.

\section{Terminology disambiguation: methodology and related notions}

(a) From the point of view of the considerations presented in this paper, it is necessary to clarify the terms used throughout. It is all the more so important as the fundamental notions, such as methodology, method, procedure, technique and tool, are used inconsistently in the metalexicographic/metaterminographic literature, possibly adding to the terminological confusion already present in both disciplines (see A. AdamskaSałaciak 2018; M. Łukasik 2018: 205-206).

The definitions included in the Oxford English Dictionary are the starting point for further terminological considerations. The $O E D$ provides the following explications of the notions in question: 
Methodology: the branch of knowledge that deals with method generally or with the methods of a particular discipline or field of study [and] the study of the direction and implications of empirical research, or of suitability of the techniques employed in it; (more generally) a method or body of methods used in a particular field of study or activity.

Method: 3.a. A special form of procedure or characteristic set of procedures employed (more or less systematically) in an intellectual discipline or field of study as a mode of investigation and inquiry, or of teaching and exposition.

Procedure: 1.a. The fact or manner of proceeding with any action, or in any circumstance or situation; the performance of particular actions, esp. considered in regard to method; practice, conduct. Also: the established or prescribed way of doing something. 2.a. A particular course or mode of action; an established or prescribed way of doing something; (also) an instance of this; a process, a proceeding.

Technique: 3. [A] particular way of carrying out an experiment, procedure, or task, esp. in a scientific discipline or a craft; a technical or scientific method.

Tool: 2.a. Anything used in the manner of a tool; a thing (concrete or abstract) with which some operation is performed; a means of effecting something; an instrument. (OED online)

Although the definitions presented above help to resolve some of the ambiguities, the notions of methodology and method seem to require further explanation, especially as the two concepts are most frequently used incorrectly.

According to A Dictionary of Research Methodology and Statistics in Applied Linguistics, research methodology is:

a theory of how inquiry should occur. Research methodology defines the kinds of problems that are worth investigating and frames them, determines what research approaches and research methods to use, and also how to understand what constitutes a legitimate and warranted explanation. Research methodology involves such general activities as identifying problems, review of the literature, formulating hypotheses, procedure for testing hypotheses, measurement, data collection, analysis of data, interpreting results, and drawing conclusions. Researchers need to understand the assumptions underlying various techniques and they need to know the criteria by which they can decide that certain techniques and procedures will be applicable to certain problems and others will not (H. Tavakoli 2012: 548-549).

Generally, the explanation presented above seems to be in line with general views on methodology presented in the philosophy of science. As S. Kamiński puts it

[...] methodology of science deals with the functional aspect of science. In principle, it is a theory of research methods. It rarely appears as a strict theory or has a uniform structure. As a matter of fact, it analyses not only the research procedures, but also research results (terms, theses, theories), which links it to the semiotics of logic. [...] The methodology of a science is concerned with the logical reconstruction of actual methods used in research (deducing and revealing their principles), the identification of their strengths and weaknesses in order to construct a hypothetical methodological model [...]. (S. Kamiński 1981: 39 - translation mine - M.Ł.)

What transpires from the considerations presented above is that methodology in general can be seen as a theory and an overall scheme of scientific work. It can be said 
that the aim of methodology is to build general models of optimal (rational and effective) scientific work and their validation from the point of view of the goal(s) that the science attempts to achieve (S. Kamiński 1981: 40). Yet, as has been outlined in the first section of this paper, methodology is also a design and control tool, whose directives translate to practical applications. Therefore, the following methodological issues are brought to light when a specific study is considered (H. Tavakoli 2012: 549):

(a) methods and logic behind methods in the context of a specific study,

(b) the rationale of the study,

(c) the manner in which the research problem has been defined,

(d) the manner and the reason why the hypothesis has been formulated,

(e) the kind of data that have been collected with a particular method,

(f) the particular technique of data analysis that has been adopted.

When considering the general methodological perspective of a science, the above list needs to be supplemented, inter alia, by the study of the object of research, its features and relations between the features. Besides, one of the objectives of methodology is to align a particular science with general principles of scientific work. What needs to be borne in mind is that in various sciences, but also within the same science but at different stages of its development, the object of research may be related to different aspects/ parts of reality (as already outlined above). Therefore, the methodological rigours are relative and subject to evolution.

Also, the results of a methodological review might be different for various types of scientific work. Moreover, it can sometimes be difficult to precisely determine the research procedure. Therefore, it may not be feasible to draft a precise theory of research methods if the latter have not yet been clearly determined (cf. S. Kamiński 1981: 41). Furthermore, it might be impossible to draw a clear line between scientific and non-scientific way of learning about things (F. Grucza 2017: 29).

(b) The notion of method is often defined as "a systematic and rigorous way of collecting and analyzing information", and involves the use of a wide variety of instruments to gather data, including test, questionnaire, rating scale, observation, interview, verbal report, diary study, discourse analysis, etc. (H. Tavakoli 2012: 548).

A more comprehensive explanation of the notion comes from H.E. Wiegand, who writes:

Eine Methode ist eine geordnete Menge von Handlungsanweisungen, deren Befolgung in mindestens einer geordneten Reihenfolge und unter Beachtung aller methodenzugehöriger Korrektheitsbedingungen erfolgen muss, damit das gewünschte Ergebnis erhältlich ist. Die geordnete Befolgung der Handlungsanweisungen, die zu einer Methode gehören, ist die Methodenanwendung. Von einem Forscher, der eine bestimmte Methode angewandt hat, die aus n Handlungsanweisungen besteht, kann verständlich gesagt werden, dass er mit $\mathrm{n}$ Schritten einen methodischen Weg gegangen oder dass er in $\mathrm{n}$ Schritten methodisch vorgegangen ist (H.E. Wiegand 2010: 251-252).

An important conclusion can already be drawn from both definitions presented above, namely that methods follow a scientifically-defined scheme of activities. As A. Kamiński points out, a research method is a set of theoretically-justified conceptual and instrumental steps that encompass the entirety of a researcher's actions, aimed at 
solving a particular research problem. Meanwhile, a research technique is a set of practical steps, or actions, subordinated to carefully-elaborated directives, that allow the researcher to obtain optimally verifiable information, opinions, facts, etc. The choice of research techniques is therefore dependent on, and conditioned by, the method adopted. From this perspective, a research tool is a means to realising a research technique (A. Kamiński 1974: 5 ff) ${ }^{3}$. These explications clearly delineate method from methodology, and method from research technique and tool, which seems to be missing from the definition by $\mathrm{H}$. Tavakoli. It also needs to be noted that some scholars emphasise that the scientific method "is often misrepresented as a fixed sequence of steps rather than being seen what it truly is, 'a highly variable and creative process"' (H.G. Gauch Jr. 2003: 3).

(c) What follows from the considerations presented in this section is that there is an apparent hierarchy between the notions outlined, with methodology being the overarching concept defining the entire enterprise of scientific work. This means that in light of a particular task, methodology will detail the method(s) that can/ should be used in particular research areas, while a particular research context (e.g. a specific research question) will determine the research procedure along with a set of techniques and tools. Definitely, the set of methods will be different when used in relation to concrete and mental/ theoretical (=model) entities, even if the latter may mimic the former on various levels and exhibit similar parameters (consider actual terminographic works and their theoretical models).

\section{Methodology of metaterminography}

(a) As in the case of any other science, metaterminography also develops its own methodology. The rationale behind undertaking discussion of the methodology of metaterminography rather than one of terminography is that the former is in fact the science that undertakes theoretical and methodological considerations important from the perspective of the practical enterprise of specialised dictionary-making ${ }^{4}$.

Some issues connected with the methodology of metaterminorgaphy have already been discussed, and were summarised in my previous paper (see M. Łukasik 2018). Among the most fundamental from the perspective of the present paper are the considerations on the object of research and the overarching goal of metaterminography.

(b) The object of research in metaterminography is the terminographic work, while the ultimate goal of metaterminography is to produce descriptive, parametric and other data that would facilitate the construction of ever better terminographic works

\footnotetext{
${ }^{3}$ The term 'method' is often used to mean 'research technique' and/or 'research tool', which from the methodological perspective constitutes an undesirable lack of precision of the language used (see section 1). For example, H. Nesi, citing H.A. Welker, considers the following "methods of investigating dictionary use: (1) Questionnaire surveys. (2) Interviews. (3) Observation. (4) Protocols. (5) Tests and experiments. (6) Log files" (H. Nesi 2013: 63, emphasis is mine, M.Ł.).

${ }^{4}$ The term 'dictionary' is used here in the wide sense and is equivalent to a terminographic work.
} 
(M. Łukasik 2018: 199-200). In this way, metaterminography produces knowledge that carries the applicative potential.

From the teleological viewpoint, the terminographic work (i.e. any product of terminographic activity) should always be the central element of metaterminographic study. Accordingly, all metaterminographic investigations, as defined by the various areas of its study, such as, e.g. user and use investigations or systematic dictionary research, are subjected to the primary goal of metaterminography. This means that the research results obtained in such studies should always produce data that could be directly or indirectly used in the design and construction of better terminographic works. Yet, because the research methods and the type of data obtained are different for various types of, and at different stages of, metaterminographic studies, it might be necessary to develop an intermediate set of methods, procedures, techniques and tools to bridge all levels/stages of research. An illustrative example comes from user research, which primarily employs methods, procedures, techniques and tools of social science (and also to some extent those of psychology, language/ knowledge acquisition studies, etc.). The data obtained in such studies have to be somehow translated to a set of new/ modified dictionary parameters that metaterminography promises to deliver in order to fulfil its ultimate research goal. In some instances, the metaterminographic data need to be processed even further so as to become compatible with the methods used by practical terminography, possibly giving rise to another set of intermediate methods, procedures, etc. These intermediate levels are fundamental in preventing unwarranted conjectures and in ensuring scientific reliability, also achievable by quantification of the data.

(c) From the point of view of its independence as a science, metaterminography differs from metalexicography on account of its different object of research. While the latter deals with the lexicographic work, the former is concerned with the terminographic work. Even if the two types of works generally share some features, they also differ in many other aspects, for example as regards the parameter of the amount and quality of (specialised) knowledge transferred by various structural elements of the final product. Given their object of research, neither terminography nor metaterminography can be seen as (sub)disciplines of terminology, lexicology or linguistics (for a detailed discussion, see M. Łukasik 2018: 198-200).

(d) The notion of parameter comes to the fore in methodological deliberations. Parameter is seen as any intra- or extra-lexicographical feature that is/ can be analysed within metalexicography/metaterminography. Most importantly, such parameters have to be (meta)lexicographically-/ (meta)terminographically-relevant, which means that their analysis should expand the researcher's knowledge about the past, present or future state of the object of research and contribute to the elaboration of data that will make the attainment of the goal of (meta)lexicography/ (meta)terminography possible. Definitely, the number and type of parameters taken into account in a particular study will depend on the area of (meta)lexicographic/ (meta)terminographic research, kind of particular study, the research question posed and the type of terminographic work considered (cf. J. Lukszyn/ W. Zmarzer 2006: 157). In light of the present considerations, any potential inconsistency with regard to the system of parameters calls 
for a methodological verification and clarification, possibly leading to new (improved) parameters or types of parameters.

(e) Since metaterminography also envisages elaboration of the theoretical underpinnings and methodology, including the development of theoretical and methodological principles of terminographic (=practical) activity (M. Lukasik 2018: 200), it comes as no surprise that the methodology of methaterminography is also an overarching mechanism ensuring adequate (i.e. the highest achievable) level of scientific rigour in all terminographic undertakings. Also, being self-reflective, metaterminography should also ensure validation of its own methodology. By perfecting its methodology, which is a goal attainable through its alignment with general scientific principles, such as those outlined in Section 1 of this paper, metaterminography better fulfils its overarching goal.

However, not all of the methods, procedures, techniques, etc. found in terminography and metaterminography can be subjected to the methodological scrutiny of the latter, mainly because metaterminography may not be competent in their evaluation, development, etc., in so far as the methods, procedures, techniques, etc. can belong to a methodology of another science or a technical process.

Furthermore, as in the case of any other science, the methodology of metaterminography is changing over time, and therefore from the diachronic perspective it may be difficult to determine its continuity. This can stem from the fact that compared to the practical business of dictionary-making, systematic metaterminographic studies are not only relatively recent, but also patchy. Another issue might be that at various stages of its development, metaterminography has adopted various scientific paradigms, for example the principles as well as methods, techniques, etc. of the Vienna school of terminology throughout most of the $20^{\text {th }}$ century (cf. H. Felber/ G. Budin 1989).

(f) One of the fundamental assumptions made in metaterminographic methodology is that all data obtained in are quantifiable. This also pertains to data that are usually seen as 'qualitative'. To allow quantification of such data, they should usually be broken down to constituent data elements that can then be quantified (consider user data vis-à-vis the parameter of dictionary usefulness). However, all variables and interdependencies must be identified at the design stage of a study so as to allow a choice of proper research techniques and tools as well as measuring instruments.

\section{Methods in metaterminography}

\subsection{Fundamental methods in metaterminography}

(a) One of the first attempts to summarise the methods used in lexicography and metalexicography comes from M. Mann and S.J. Schierholz (2014) and S.J. Schierholz (2015). Other scholars outline methods specific to various areas of metalexicographic studies, such as: the methods employed in research of dictionary use and users (e.g. H. Bergenholtz/ M. Johnsen 2013, H.A. Welker 2013, C. Müller-Spitzer 2014) or dictionary criticism (K. Akasu 2013; P. Swanepoel 2017).

Some assumptions presented by S.J. Schierholz (2015) will be taken as a point of 
departure for further considerations on the methods in metalexicography and metaterminography. According to the scholar, two theories, namely an action theory and a linguistic theory, provide for the choice of methods in metalexicography. According to the author "[t]he action theory plays a decisive role for the subject "dictionary" because dictionaries are produced for the purpose of being used. Therefore, the actions of a potential user of a dictionary are in the center of the considerations", whereas "[t]he linguistic theory plays a decisive role since, not only in language dictionaries but also in subject dictionaries, linguistic expressions are described in/ with linguistic terms" (S.J. Schierholz 2015: 325).

From the methodological perspective, S.J. Schierholz's proposal seems to be inaccurate. First and foremost, since this is the object of research that determines the methods with which it is studied, it goes without saying that different classes of objects may require different research methods, although there may be methods that can effectively be used to study different classes of objects. The objects that are studied by metalexicography and metaterminography are lexicographic and terminographic works, respectively. As has already been mentioned in the preceding paragraphs, only by precisely defining the object of research, can one undertake a meaningful discussion regarding the methods that are supposed to be employed in the study of such objects. Form the ontological point of view, the lexicographic/ terminographic work is a complex textual object with a primary function of communicating information. Hence, it shares features with other texts, including the structural building blocks of text, i.e. mega-, macro-, medio- and microstructure, although in (meta)lexicography/ (meta)terminography these compositional elements are defined in the narrow, i.e. dictionary-centred, sense. It therefore follows that the primary theories that could be the sources for any method development are the theory of text and the theory of information. Consequently, there is little ground to the claim that the methods based on action theory or linguistic theory should be the dominant ones in metalexicographic investigations. This argument seems to be also valid in view of the various methods used in different types of studies undertaken within particular metalexicographic/ metaterminographic areas of enquiry (see below).

(b) A fundamental finding follows from the considerations presented above, namely that the methods that primarily belong to (meta)lexicography and (meta)terminography are those that directly deal with parameters of lexicographic and terminographic works. All other methods are seen here as complementary, although equally significant and indispensable (e.g. corpus linguistics methods or methods of user studies). As has already been emphasised, it might be necessary to develop intermediate (connecting) methods to link the different types of data produced by distinctive research methods.

Only a few methods mentioned in the literature may be said to be genuinely the core metalexicographic/ metaterminographic ones. Two of such methods within metalexicography, which can also be applied by metaterminography, have been suggested by H.E. Wiegand (2010) and include the text segmentation methods and the structure 
constructing methods ${ }^{5}$. In principle, the former take a dictionary article as a starting point, analyse its typographical marking and identify the elements of the entry along with their function, which may be independent or may be part of a larger element with its own y function. On their part, the structure constructing methods take the elements identified by the text segmentation methods to describe and investigate the structure and hierarchy of the elements. In this way, the structural building blocks of a lexicographic/ terminographic work, e.g. the macro-, medio- and microstructure, among other structures, can be identified (S.J. Schierholtz 2015: 338; H.E. Wiegand 2010). Admittedly, even if the methods start from the basic typographical level and proceed with the recognition of textual elements, the subsequent identification of lexicographic structures requires background metalexicographic knowledge. In practice, the techniques used with the methods outlined would require prior drafting of a catalogue of existing and possible lexicographic components.

The text segmentation methods and the structure constructing methods represent the bottom-up approach to gathering knowledge about lexicographic/ terminographic works. As a matter of fact, all other methods of lexicographic/ terminographic analysis, (see the following section) depend on the two methods outlined, giving rise to a specific hierarchy. The methods are important not only from the perspective of the methodological completeness of the scientific investigation of the object of research, but also from a practical viewpoint, in particular where the structure of the work is difficult to identify at first glance, such as e.g. in new types of works (e.g. digital reference works). However, in practical analyses where only specific and readilyidentifiable components are analysed, such as e.g. definitions, the methods mentioned seem to be less important.

\subsection{Terminographic analysis}

Metalexicographers and metaterminographers have frequently called for systematic dictionary studies. Such investigations in the field of terminographic works in Poland were initiated in 2005 and involved the development of a research method termed terminographic analysis. The method has proven useful in the analysis of around 2,000 terminographic works published in Poland since the $19^{\text {th }}$ century ${ }^{6}$.

In principle, terminographic analysis aims to produce relevant terminographic data that can be used to compile ever better terminographic works. To this end, any investigation within the terminographic analysis should contribute a set of optimum parameters of a future terminographic work. One can distinguish between general and detailed terminographic analysis. Further, both types of terminographic analysis can be full or partial (see M. Łukasik 2010: 26ff).

(I) General terminographic analysis aims to summarise all accomplishments of terminography on a given dictionary market within a specified period of time. In par-

\footnotetext{
${ }^{5}$ In fact, the methods used in the construction or analysis of lexicographic or terminographic works do not have to originate in (meta)lexicography or (meta)terminography.

${ }^{6}$ The data are progressively made available through the Leksykografia.pl portal.
} 
ticular, the results enable metaterminographers to: (i) draft typologies of terminographic works, (ii) identify fields/ domains for which no terminographic works have been published, (iii) evaluate the global degree to which theoretical underpinnings have been put into practice, (iv) assess the global degree to which users' needs have been met, (v) determine the capacity of publishers and the dictionary market. If the data are fairly complete, they enable predictions regarding the directions of development of terminographic practice and identification of various methodological lacunae. This type of analysis also makes comparisons between different terminographic systems (e.g. of two countries) possible.

(Ia) full general terminographic analysis investigates the entirety of terminographic works published on a given dictionary market within a specified period of time. This type of study requires that the researchers carry out full detailed terminographic analysis to allow meaningful generalisations,

(Ib) partial general terminographic analysis looks into a section of a given dictionary market within a specified period of time (i.e. taking into account a specific type of terminographic works). This type of study requires partial detailed terminographic analyses to allow meaningful generalisations.

(II) Detailed terminographic analysis focuses on individual terminographic works and their properties, with an aim of extracting fine-grained metaterminographic data, mainly related to successful and faulty terminographic solutions.

The scope of their study is defined as follows:

(IIa) full detailed terminographic analysis examines all pre-defined parameters of mega-, macro-, medio-, and microstructure of all terminographic works published on a given dictionary market within a given period of time;

(IIb) partial detailed terminographic analysis studies:

$\left(\mathrm{IIb}_{1}\right)$ a selection of pre-defined parameters of mega-, macro-, medio-, and micro structure of all terminographic works published on a given dictionary market within a given period of time, or

$\left(\mathrm{IIb}_{2}\right)$ all pre-defined parameters of mega-, macro-, medio-, and microstructure of a set of terminographic works (e.g. certain types of terminographic works and/or terminographic works of a specific field) published within a given period of time, or

$\left(\mathrm{IIb}_{3}\right)$ a selection of pre-defined parameters of mega-, macro-, medio-, and micro structure of a set of terminographic works (e.g. certain type of terminographic works and/or terminographic works of a given field) published within a given period of time. 


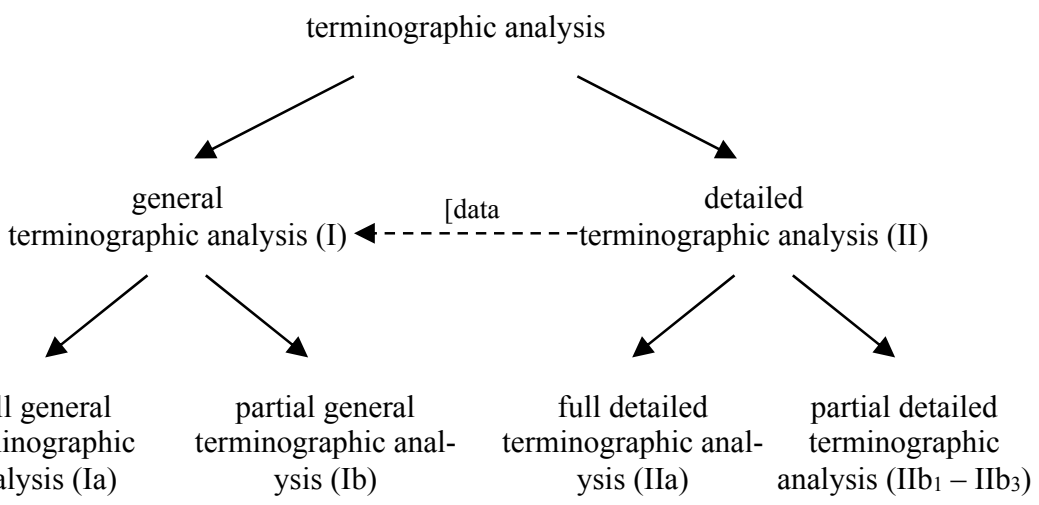

Figure 1. Constituents of the terminographic analysis.

As in the case of any other research, terminographic analysis starts with putting forward a research question. This stage is a vital starting point of the study as it determines the choice of research procedures later in the study. In particular, of major importance is the overarching type of analysis: general or detailed.

The study envisages two major stages: preliminary research, which consists in the analysis of bibliographic data, and the analysis proper, which involves the research of actual works according to a specific scheme complemented with data evaluation, if applicable.

The preliminary research amounts to gathering bibliographic information, which in its initial stage consists in the analyses of existing bibliographies, online and traditional library catalogues, peruse of bookshop offer, literature review, and Internet searches. The bibliographic data gathered include: names of authors, editors, translators, illustrators, leading institution, etc., title, alternative title(s), series title, original work title (if the work investigated is a translation/ language version), number in the series, edition/ reprint number, publisher, date of publication, place of publication, domains, languages (including languages of the outside matter), directionality, type of content carrier (book, e-book, etc.), physical description, addenda (presence and description of indexes, bibliography, etc.) as well as additional information important from the point of view of bibliographic description.

The data gathered are entered to the database and often need to be verified and often supplemented. Bibliographic data provide the first indication of the terminographic output within the research task set and may constitute the basis for preliminary quantitative results. However, there are a number of issues that need to be taken into account. First, the availability of bibliographic data can be limited and the data can be incorrect; the problem often concerns library catalogues and bibliographies. Second, the data may not provide the information required by the study. For example, the title of a work may not point its terminographic origin and therefore a work can, by mistake, be omitted. It is therefore advisable to widen bibliographic studies into terminological, rather than only terminographic/ lexicographic, resources, to use a variety of queries (e.g. based not only on titles, search keywords or domain names, but also on 
authors' names or names of publishing houses), and to complement the study with further meticulous searches in other sources.

Once the bibliographic data have been gathered, terminographic analysis proper begins. If the research question envisages a full general terminographic analysis, the detailed study of all terminographic works proceeds in a data-driven fashion, which means that there is no pre-determined set of parameters according to which the works are analysed. However, it is still necessary to define what counts as a parameter in a particular study. At this stage, the text segmentation methods and the structure constructing methods, as outlined in the preceding section, become especially useful. In principle, the parameters are identified and defined with the progressive description of each terminographic work; in practice, the starting point is a maximising set of parameters extracted from theoretical models of terminographic works, such as sets of parameters of ideal dictionaries. The parameters are then detected in a terminographic work. Any discrepancies between the features found in actual works and the model parameters may be indicative of a specific realisation of the parameter or an altogether new (type of a) parameter. In any case, model parameters serve as assessment benchmarks in subsequent stages of the analysis.

For other types of studies, partial analyses are undertaken. In such settings, the array of parameters (at least some of them) is pre-defined at the design stage: they can be the parameters excerpted from theoretical models or parameters of genuine terminographic works (if some form of comparison is attempted). The first step is the identification of the presence of the parameter in the work analysed by way of the text segmentation methods and the structure constructing methods. The next step is the definition of the parameter features and parameter quality measurement method/tool. This phase is of utmost importance as the mere presence of a parameter may not reveal much about its quality. For example, the mere existence of phonetic transcription of English terms in an entry says little about its quality; what would be necessary is the indication of the phonetic alphabet used, the consistency of its use throughout the terminographic work and information on whether it has been properly introduced to the user in the outside matter. With other types of parameters, such as the ones related to the choice of terms or term explication (definition), the definition of parameter features can become even more complicated. Similarly to the research model presented for general terminographic analysis, any discrepancies between the features of parameters found in actual works and the features of model/ other works' parameters may be indicative of a specific realisation of the parameter or a new (type of a) parameter. Again, model parameters or parameters derived from other reference works serve as assessment benchmarks in the evaluative stages of the analysis. It is worth emphasising that for any assessment, the features need to be comparable, while for the global evaluation of parameters and their features, it is useful to draft matrixes. If the study aims, for example, at the establishment of the degree to which particular parameters meet users' needs, it is first necessary to establish the link between the parameters/ data of a terminographic work and the parameters/ data linked to user and use studies. In this case, the intermediate (connecting) layer of parameters may be composed of such parameters as correctness, appropriateness, reliability, completeness, usefulness, 
or user-friendliness.

Based on the above considerations, it is possible to distinguish between three general types of investigations within terminographic analysis, namely bibliographic, quantitative and qualitative analyses. Beyond the metaterminographic methodology, each such type of study is additionally subjected to its own universal methodological principles, such as, for example, the rules of statistics in quantitative investigations (see e.g. S. Tarp 2009: 290), or the methodologies of other fields, such as, for example, those of library science or bibliography.

\section{Conclusion}

Methodology is the cornerstone of any research activity and a defining element of a science. In order to fulfil its aim, a field-specific methodology needs to be aligned with the general methodology of science, which outlines the fundamental principles of research work. Accordingly, any comprehensive methodology of a science defines and evaluates, inter alia, its object of research, research goal(s) and methods.

Reaching maturity right before our eyes, (meta)lexicography and (meta)teminography have so far struggled to convincingly prove their scientific status. One reason might be the lack of a general methodological reflection on their overall practical/ research activity. Therefore, in attempting to fill the lacuna, this paper discusses some fundamental methodological features of metaterminography. The hope is that it will contribute to the establishment of a more comprehensive methodological framework that would solidify the science and bring it closer to developing a genuine theory.

\section{References}

Adamska-Sałaciak, A. (2018), Lexicography and Theory: Clearing the Ground. In: "International Journal of Lexicography", Advance access paper, 1-19. (URL https://academic._oup.com/ijl/advance-article-ab stract/doi/1 0.1093/ij1/ecy017/ 5098422). [Accessed on: 14.02.2019].

Akasu, K. (2013), Methods in Dictionary Criticism. In: H. Jackson (ed.), The Bloomsbury Companion to Lexicography. London, 48-61.

Amopolous, P.J. (2009), Social Problem Diagnosis: A Sociopathology Identification Model. In: F. Parra-Luna (ed.), Systems Science and Cybernetics. Oxford, 160195.

Bergenholtz, H./ M. Johnsen (2013), User research in the field of electronic dictionaries: Methods, first results, proposals. In: R.H. Gouws/ U. Heid/ W. Schweickard/ H.E. Wiegand (eds.), Dictionaries. An International Encyclopedia of Lexicography: Supplementary Volume: Recent Developments with Focus on Electronic and Computational Lexicography (HSK 5.4.). Berlin/ New York, 556-568.

Czarnecki, K. (2009), Nowy leksykon metodologiczny. Sosnowiec.

Gauch Jr., H.J. (2003), Scientific method in practice. Cambridge.

Grucza, F. (2013), Lingwistyka stosowana. Historia - Zadania - Osiagnięcia. Warszawa. 
Grucza, F. (2017), Zagadnienia metalingwistyki. Lingwistyka - jej przedmiot, lingwistyka stosowana (Dzieła wybrane. Tom 8). Warszawa.

Felber, H./ G. Budin (1989), Terminologie in Theorie und Praxis. Tübingen.

Kamiński, A. (1974), Metoda, technika, procedura badawcza w pedagogice empirycznej. Wrocław.

Kamiński, S. (1981), Pojęcie nauki i klasyfikacja nauk. Lublin.

Lukszyn, J./ W. Zmarzer (2006), Teoretyczne podstawy terminologii. Warszawa.

Łukasik, M. (2010), Teksty specjalistyczne a konstruowanie terminograficzne. Warszawa. [Unpublished doctoral thesis]

Łukasik, M. (2018), Theoretical Underpinnings of Metaterminography. In: “Applied Linguistics Papers", 25/4, 195-213.

Mann, M./ S.J. Schierholz (2014), Methoden in der Lexikographie und Wörterbuchforschung. Ein Überblick mit einer Auswahlbibliographie. In: "Lexicographica" 30, 3-57.

Müller-Spitzer, C. (2014), Methoden der Wörterbuchbenutzungsforschung. In: "Lexicographica" 30, 112-151.

Nesi, H. (2013), Researching Users and Uses of Dictionaries. In: H. Jackson (ed.), The Bloomsbury Companion to Lexicography, London, 62-74.

OED online $=$ Oxford English Dictionary. (URL http://www.oed.com). [Accessed: 10.02.2019].

Pabis, S. (2009), Metodologia nauk empirycznych. 15 wykładów. Koszalin.

Rosenberg, A. (2005), Philosophy of Science. A contemporary introduction. New York/ London.

Schierholz, S.J. (2015), Methods in Lexicography and Dictionary Research. In: "Lexikos" 25, 323-352.

Such, J. (1972), O uniwersalności praw nauki. Warszawa.

Swanepoel, P. (2017), Methods in dictionary criticism. In: M. Bielińska/ S.J. Schierholz (eds.), Wörterbuchkritik - Dictionary Criticism (Lexicographica. Series Maior 152), Berlin, 81-112.

Tarp, S. (2009), Reflections on Lexicographical User Research. In: "Lexikos" 19, 275-296.

Tavakoli, H. (2012), A Dictionary of Research Methodology and Statistics in Applied Linguistics. Teheran.

Welker, H. A. (2013), Methods in Research of Dictionary Use. In: R.H.Gouws/ U. Heid/ W. Schweickard/ H.E. Wiegand (eds.), Dictionaries. An International Encyclopedia of Lexicography: Supplementary Volume: Recent Developments with Focus on Electronic and Computational Lexicography (HSK 5.4.). Berlin/ New York, 540-547.

Wiegand, H.E. (2010), Zur Methodologie der Systematischen Wörterbuchforschung: Ausgewählte Untersuchungs- und Darstellungsmethoden für die Wörterbuchform. In: "Lexicographica" 26, 249-330. 